\title{
Balance of Concerns: Satisfactory Pre-Anesthetic Patient Education and the Extent of Patient Worries
}

\author{
Joerg Schnoor*, Ulrike Reuter, Nils Engelmann, Ullrich Burkhardt \\ Department of Anesthesiology and Intensive Care Medicine, University Hospital Leipzig, Leipzig, Germany. \\ Email: *joerg.schnoor@medizin.uni-leipzig.de
}

Received September $24^{\text {th }}$, 2013; revised October $17^{\text {th }}, 2013$; accepted October $29^{\text {th }}, 2013$

Copyright (c) 2013 Joerg Schnoor et al. This is an open access article distributed under the Creative Commons Attribution License, which permits unrestricted use, distribution, and reproduction in any medium, provided the original work is properly cited.

\begin{abstract}
Controversy exists whether or not patient's concerns regarding anesthetics can be reduced by face-to-face pre-assessment with an anesthetist. Thus we were looking at concerns patients had before and after such a consultation. Patient satisfaction was rated by a validated questionnaire. A four-staged Likert-scale was used to quantify the extent of patients concerns. The totaling 461 patients were overall highly satisfied. 448 patients had "nil” to "minimal” concerns. After the assessment, 106 patients stated their concerns had been lessened ( $p<0.001)$. Having gone through the anesthetic pre-assessment center, 99.1\% of all patients reported no considerable concerns regarding anesthetics whatsoever. A high level of patient satisfaction does not constitute a low level of concerns patients may hold over anesthetics, although a pre-operative consultation mitigated these concerns by $23 \%$, whilst for $9 \%$ of all patients this pre-assessment led to a higher level of concerns.
\end{abstract}

Keywords: Patient Worries; Patient Concerns; Preoperative Patient Assessment; Resilience; Anxiolysis

\section{Introduction}

More and more hospitals take patient satisfaction into consideration when evaluating outcome of hospital stays. But especially for pre-assessment centers such an approach is not always helpful. About $90 \%$ of all patients are happy at the time of getting pre-assessed. However, this can be too optimistic taking into consideration the dependence on and subjection to the carer and treatment, as demonstrated in the wellbeing paradox [1,2].

$30 \%-60 \%$ of all patients had concerns or even fears prior to any operation [3]. Whilst concerns regarding the operation and those regarding anesthetics are hard to differ, a pre-aesthetic consultation can reduce these concerns by up to $60 \%$ [4-9]. Unfortunately $30 \%$ of all patients saw their concerns soaring after such a consultation [10]. Although patient satisfaction is more and more embraced by hospitals as another tool for measurement of quality, patients concerns remain a somewhat unchartered territory.

We aimed at quantifying the impact an anesthetic preassessment had on patients concerns whilst otherwise being satisfied. Therefore, a validated questionnaire had

${ }^{*}$ Corresponding author. to be filled out by patients prior and after the pre-assessment rating patients' worries.

\section{Method}

After approval from the local Ethics Commission we conducted our study form July to September 2011 in the anesthetic pre-assessment center of the University Hospital Leipzig. Written informed consent was obtained prior to the anesthetic consultation. Patients were recruited from 12 different surgical specialties (Visceral-, Transplant-, Thoracic- and Vascular Surgery, Trauma and Plastic surgery, Orthopedics, Neurosurgery, OBs/ GYNE, Urology, ENT, Maxillo Facial surgery, Dermatology, Radiotherapy, Virology and Allergology). Patients being bedbound or contagious were not included.

We included all patients from 18 years of age upwards, ranging in ASA classification I-IV, presenting them at that time in the anesthetic pre-assessment center. Selection of patients was conducted weekdays, depending on availability of staff trained for this survey. Criteria for dismissal of participation were aged below 18, missing power of attorney, previous participation when undergoing revision of surgery, lack of communication, and pa- 
tients’ refusal to participate.

Patients were asked to choose from one of the following 4 stages of concerns displayed on a four-staged Likert-scale $(4=$ nil concerns, $3=$ minimal concerns $2=$ many concerns, 1 = great concerns) before and after the face-to-face consultation with an anesthetist [11]. Further on we rated patients' satisfaction regarding the anesthetic pre-assessment consultation using a validated questionnaire (ZUF-8), which is the German adaptation to the American CSQ-8 questionnaire (Table 1) [12-14].

Statistical analysis was computer based, using SPSS ${ }^{\circledR}$ Statistics, Version 20, IBM ${ }^{\circledR}$. The paired t-Test was utilized for pre-post comparison within any random sample. Group comparison was conducted using both the MannWhitney-U test and the Fisher's exact test, respectively. Data is displayed as an Arithmetic Mean and Standard Deviation, unless stated otherwise. Level of Statistical Significance was determined as 5\% ( $<<0.05)$.

\section{Results}

Of 587 patients, 461 (78.5\%) completed records were obtained. Median age was $52.4 \pm 16.5$ years, out of which $46.2 \%$ were of female gender. Median ASA classification was II (Figure 1). Overall patient satisfaction was high (ZUF-8: $29.4 \pm$ 2.5; Minimum-Maximum 20 - 32, Figures 2 and 3).

Prior to the anesthetic pre-assessments 448 (97.2\%) stated to have "nil" to "minimal" concerns regarding anesthesia (Figure 4). This figure rose to 457 patients (99.1\%; $3.72 \pm 0.47 ; t=5.27$; Degrees of Freedom $=460$; $\mathrm{p}<0.001$, Figure 5). Opposite to that the number of patients with "many" concerns (12 patients) was reduced down to 4 patients. The single patient with, "great" con-

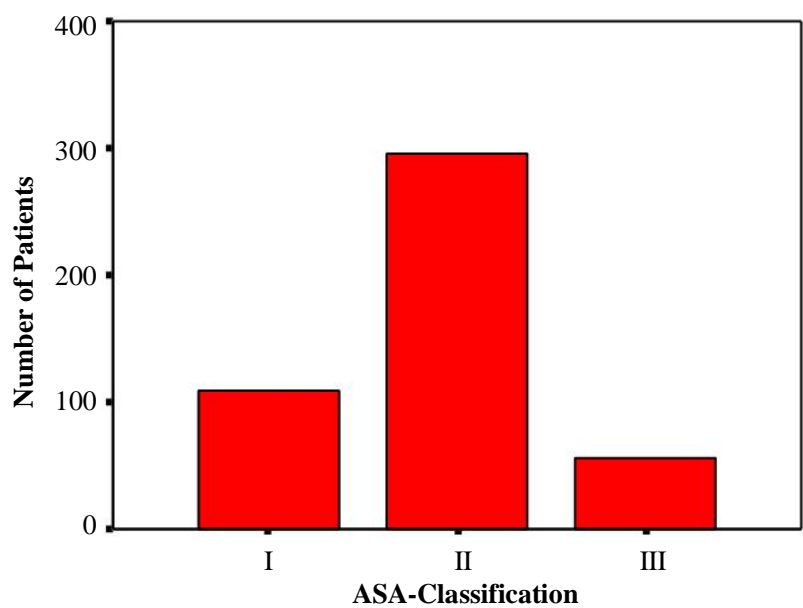

Figure 1. Distribution of ASA classification.

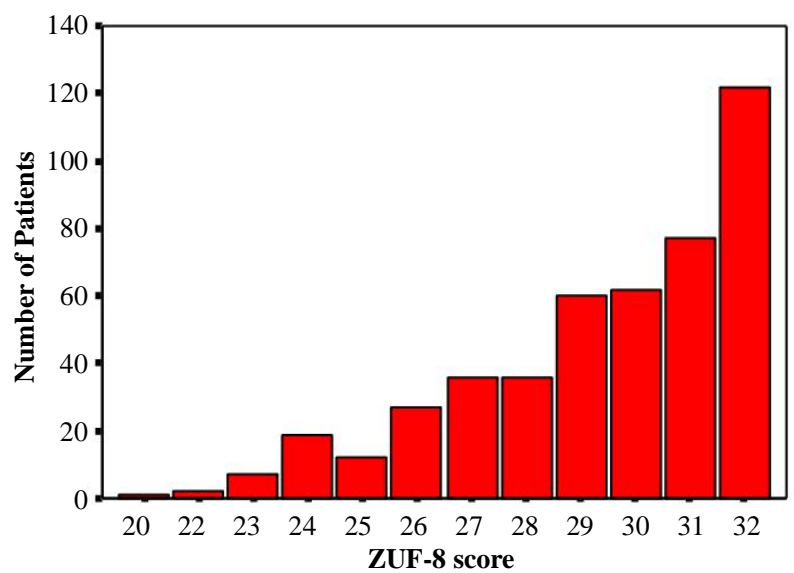

Figure 2. Distribution of patient satisfaction according to ZUF-8-score after anesthetic pre-assessment (ZUF-8-Questionnaire, 8 - 32 possible points summarized).

Table 1. Overall satisfaction with the anesthetic pre-assessment, determined by a modified questionnaire, adapted to the preassessment center (ZUF-8 [12]).

1) To what extend has the anesthetic pre-assessment center catered for your need?

( 4 = catered for almost all my need; 3 = catered for most of my need; 2 = catered for just a few of my need; 1 = has not catered for my need)

2) How would you rate the quality of your anesthetic consultation?

(4 = excellent; 3 = good; 2 = not so good; 1 = bad)

3) How satisfied were you with the overall content of your pre-assessment?

(4 = satisfied; 3 = mostly satisfied; 2 = with reservations; 1 = not satisfied)

4) Has the anesthetics consultation helped you to revaluate your concerns regarding the anesthetics procedure?

( 4 = yes, it has been very helpful; 3 = it helped a little; 2 = it did not help at all; $1=$ no, it made it even more difficult to deal with)

5) Would you opt for this anesthetics department again if you had to undergo other anesthetics?

(4 = definitely; 3 = generally speaking, yes; 2 = generally speaking, no; 1 = absolutely not)

6) Would you recommend the anesthetic department to a friend if he or she needed an anesthetic?

(4 = definitely; 3 = generally speaking, yes; 2 = generally speaking, no; 1 = absolutely not)

7) Would you come back to the University Hospital Leipzig if you were in need of medical attention?

(4 = definitely; 3 = generally speaking, yes; 2 = generally speaking, no; 1 = absolutely not)

8) Would you recommend the University Hospital Leipzig to a friend if he or she needed medical attention?

( 4 = definitely; 3 = generally speaking, yes; 2 = generally speaking, no; 1 = absolutely not)

The sum of achieved points leads to the ZUF-8 rating (Minimum-Maximum: 8 - 32 points). 


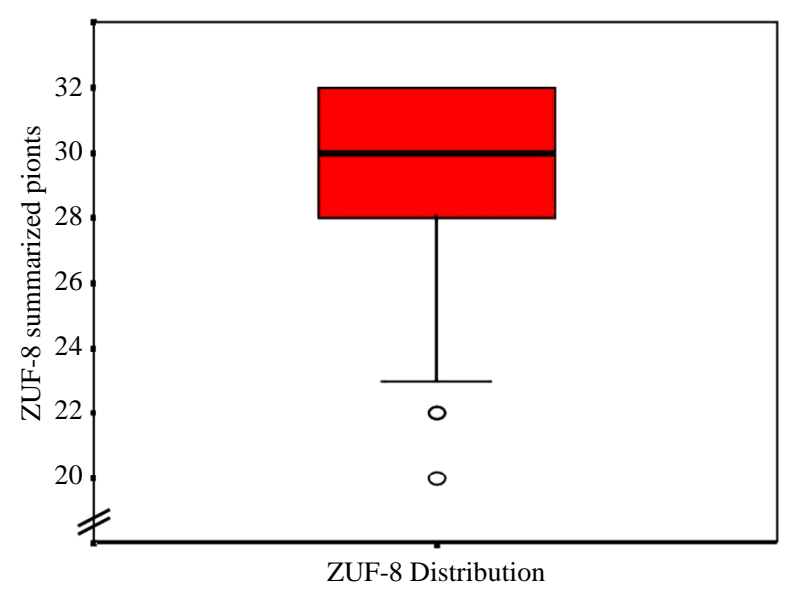

Figure 3. Patient satisfaction (box plot) after the anesthetic pre-assessment (ZUF-8-Questionnaire, 8 - 32 possible points summarized).

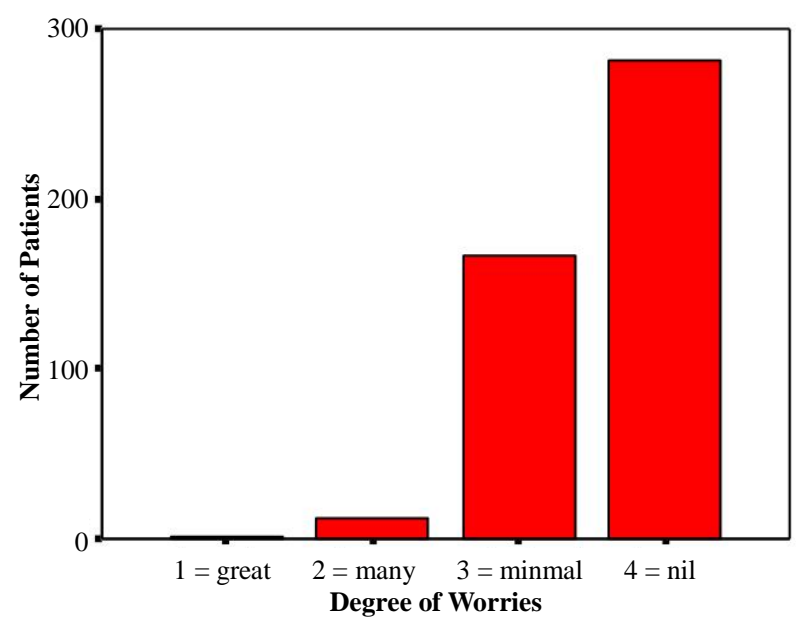

Figure 4. Patients concerns prior to anesthetic pre-assessment.

cerns felt relief and subsequently downgraded his concerns to the "many" concerns level.

A total of 42 patients announced an increase in concerns felt after the anesthetic consultation. 41 of these patients went from "nil" to a "minimal" concerns level. A single patient went from "nil" concerns to "great" concerns after having been pre-assessed by an anesthetist. The group of patients showing an increase in concerns (n $=42$ ) simultaneously displayed a slightly higher level of overall satisfaction (ZUF-8: $30.5 \pm 1.6$ vs. $29.3 \pm 2.6$; p= 0.01 ). Other than that no statistically significant difference was found regarding the variables of gender (Fischer's exact test, $\mathrm{p}=0.303$ ), age, BMI, and ASA (MannWhitney-U test with $\mathrm{p}=0.907, \mathrm{p}=0.802$, and $\mathrm{p}=$ 0.737).

\section{Discussion}

In line with expectations, the results demonstrate a high

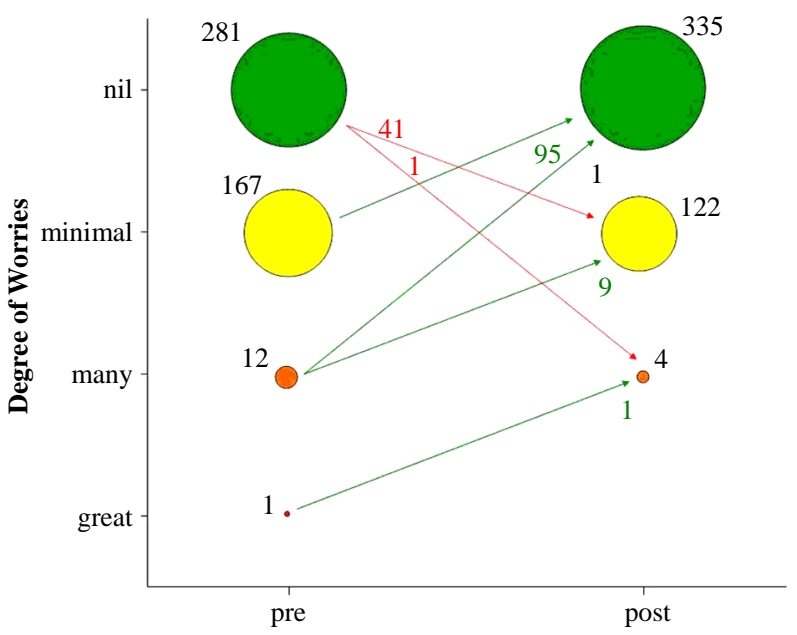

Figure 5. Summary of concerns of individual patients prior and after anesthetic pre-assessment. Numeric characters und sizes of circle display number of patients. Green arrows indicate a reduction in concerns, a red arrow an increase in concerns patients had. Numeric characters of arrows display number of patients as net movement.

level of patient satisfaction regarding the anesthetic preassessment consultation. The overwhelming number of patients had nil to minimal concerns regarding the upcoming anesthetic, and this number increased by 6\% up to $99 \%$ of all patients after consulting an anesthetist. 13 patients with "many" to "great" concerns could be comforted, whilst $9 \%$ of all patients had their level of concerns raised, one even comprehensively.

Having concerns and fear are primeval feelings. The roots of these can be found in man's perception of his life span limiting his existence. Vulnerability of body and soul, a sense of imperfection, and finally, the prospect of inevitable death all fuel doubt, concerns, and fears. Outside of Psychopathology definition of these is subject to debate. However, psychologically ordinary patients perceive "concerns" as disconcerting forethoughts, without any reassurances whether the anticipated realistic or unrealistic scenarios can be dealt with accordingly or not. Fear, in its true meaning, is perceived as imminence or even intimidation, unidirectional, even unmotivated, with or without a comprehensible source of this, whilst "Fear" has a present source and magnitude [15].

\subsection{Patients' Perspective}

Patients favor a reduction of pre-operative concerns, notably by consulting a doctor [16]. A previous study though found an unintentional increase in patients' concerns in up to $30 \%$ after such a consultation [10]. Our study showed a lower rate than this; still despite a high level of patient satisfaction almost every 10th patient voiced an increased level of concerns after the anesthetic pre-assessment. However, previous studies found other, 
non anesthetic related sources, notably being away from home and relatives, waiting time on operation, loss of autonomy, as well as ensuing physical and psychological ramifications from prospective surgery $[17,18]$.

Opposingly, multiple factors can reduce pre-operative concerns of patients. An empathetically conducted preassessment, an adequate amount of information, as well as the manner of the consultation all attribute positively towards reducing patients' concerns $[19,20]$. A religious or spiritual background, a supportive social network, visiting relatives, acupressure and music are perceived as alleviating and comforting. A patient's cultural background contributing to his coping strategies must be taken into consideration as well [21-23].

Individual coping strategies seem to be of great importance. "Resilience" describes an individual's ability to utilize ones own resources as well as those of relatives and other social networks, to cope and overcome stress and adversity, and possibly even gain posttraumatic growth [24,25].

Individual levels of resilience determine how successful a patient copes with stress. A hospital stay or scheduled operation can instigate serious thoughts regarding ones own mortality. However, in a busy hospital schedule time to dwell on these thoughts and finding answers to these questions is naturally rather limited. Additionally, ones concept of life previously taken for granted may now become acutely destabilized.

Furthermore, some patients may realize the full account of surgical ramifications for the first time after an anesthetic pre-assessment, with little to no time to apprehend this in detail. Being unprepared and left with aspects threatening their future wellbeing, concerns and even fear may develop despite any empathetically conducted anesthetic consultation.

\subsection{Corporate Perspective}

In the German health care system patients are seen as customers shopping for services. However, in health care markets a patient seldom approaches a medical professional on an even level, as his medical condition puts him in a position of need and dependency. Furthermore, due to the nature of illnesses, patients neither have time nor in-depth knowledge to compare or even "choose" from a variety of independently operating health care providers, whilst being in need of medical attention.

German anesthetic pre-assessment centers operate under a strict time frame, and the pre-assessment is conducted under considerable time pressure, worsened by ever increasing new legislative requirements for documentation. A personalized consultation, that has to be conducted obeying all legal aspects, guidelines and record keeping requirements, leaves little room to instigate trust. Given the fact that in Germany the pre-assessing anesthetist seldom performs the anesthetic himself, as theatre and pre-assessment allocation happens on a day to day basis, the patient is deprived of any chance to get to know "his" anesthetist, to be there on the day of surgery. This modern fragmentation of work, saving GBP 5.62 per patient each, is significantly working against building trust between doctors and patients, hampering bonding on a professional level, and subsequently reducing the ability of medical professionals to mitigate patients' concerns [26,27].

Quality Management utilizes patient satisfaction as a tool to measure outcome. In this respect patients can only measure and hence rate direct medical interaction, which is exclusively rendered by doctors and nurses. From a patient's point of view, friendly and professional staff makes all the difference, and inter-personal communication helps to reduce patients concerns. Staff under considerable amount of pressure cannot contribute to building trust and confidence, nor help mitigate patients' concerns. The question arises how a modern day hospitals schedule can accommodate for the need to build trust by spending more time with patients.

\subsection{Limitations of This Study}

This study demonstrates various limitations. An additional person presents for recording the pre-assessment study and the advanced information of all participants limits comparison to real life pre-assessment.

Patient's concerns were rated by the Likert-scale. To not further interfere with clinical routine we dismissed the use of standardized rows of questions, displaying the routine approach of pre-assessment instead. This leads to a stinted comparability with bibliographical references.

The validated ZUF-8 score rated the degree of satisfaction. Nevertheless, this score is not one of the recently recommended scores for rating satisfaction with preassessment [28]. Consequently, the comparability of our results might be limited in the future.

The individual coping strategies and reasons for concerns of patients were not surveyed. Thus, an individual cause-effect relationship could not be displayed.

The manner of each anesthetist's assessment was not taken into consideration. Whether these conversations fulfilled criteria such as appreciation, authenticity, empathy, and active listening, was not considered [29]. The results of pre-assessment do not conclude on empathy and patient centered communication displayed by each anesthetist.

Altogether, a high level of patient satisfaction does not conclude to a low level of concerns patients may hold. Nevertheless, mitigation of patient concerns was achieved one forth of all patients, whilst nearly 1 out of 10 patients emerged from pre-assessment with more concerns than before. The reasons for concerns leading to a 
negative balance of these seem to be multi-factorial, and as such are difficult to identify. However, a patient centered approach to presenting information relevant for giving informed consent should be sought, helping patients to adapt an optimistic manner of dealing with their concerns. To achieve this, more time spent with each patient is desirable; something a DRG based system will have a hard time to generate.

\section{REFERENCES}

[1] P. Herschbach, "The 'Well-being paradox' in Quailty-ofLife Research,” Psychotherapie, Psychosomatik, Medizinische Psychologie, Vol. 52, No. 3-4, 2002, pp. 141-150. http://dx.doi.org/10.1055/s-2002-24953

[2] M. Bauer, H. Böhrer, G. Aichele, A. Bach and E. Martin, "Measuring Patient Satisfaction with Anaesthesia: Perioperative Questionnaire versus Standardised Face-to-Face Interview," Acta Anaesthesiologica Scandinavica, Vol. 45, No. 1, 2001, pp. 65-72.

http://dx.doi.org/10.1034/j.1399-6576.2001.450111.x

[3] K. Pokharel, B. Battharei, M. Tripathi, S. Khatiwada and A. Subedi, "Nepalese Patient's Anxiety and Concerns before Surgery,” Journal of Clinical Anesthesia, Vol. 23, No 5, 2011, pp. 372-378. http://dx.doi.org/10.1016/j.jclinane.2010.12.011

[4] A. R. Braun, K. Leslie, C. Morgan and S. Bugler, "Patients' Knowledge of the Qualifications and Roles of Anaesthetists," Anaesthesia and Intensive Care, Vol. 35, No. 4, 2007, pp. 570-574.

[5] C. H. Kindler, L. Szirt, D. Sommer, R. Häusler and W. Langewitz, "A Quantitative Analysis of Anaesthetist-Patient Communication during the Pre-Operative Visit,” Anaesthesia, Vol. 60, No. 1, 2005, pp. 53-59. http://dx.doi.org/10.1111/j.1365-2044.2004.03995.x

[6] M. Mitchell, "General Anaesthesia and Day-Case Patient Anxiety,” Journal of Advanced Nursing, Vol. 66, No. 5, 2010, pp. 1059-1071. http://dx.doi.org/10.1111/j.1365-2648.2010.05266.x

[7] E. Lam, M. Lee, R. Brull and D. T. Wong, "Effect of Anesthesia Consultation on Patients' Preoperative Concerns," Canadian Journal of Anaesthesia, Vol. 54, No. 10, 2007, pp. 852-853. http://dx.doi.org/10.1007/BF03021718

[8] M. Yilmaz, H. Sezer, H. Gürler and M. Bekar, "Predictors of Preoperative Anxiety in Surgical Inpatients,” Journal of Clinical Nursing, Vol. 21, No. 7-8, 2012, pp. 956-964. http://dx.doi.org/10.1111/j.1365-2702.2011.03799.x

[9] P. Mavridou, V. Dimitriou, A. Manataki, E. Arnaoutoglou and G. Papadopoulos, "Patient's Anxiety and Fear of Anesthesia: Effect of Gender, Age, Education, and Previous Experience of Anesthesia. A Survey of $400 \mathrm{~Pa}-$ tients,” Journal of Anesthesia, Vol. 27, No. 1, 2013, pp. 104-108. http://dx.doi.org/10.1007/s00540-012-1460-0

[10] T. Löwer, C. Krier and A. Henn-Beilharz, "Der Einfluss des Prämedikationsgesprächs auf das Preoperative Angstverhalten des Patienten," Anasthesiologie, Intensivmedmedizin, Notfallmedmedizin, Schmerzthertherapie, Vol.
34, No. 3, 1993, pp. 121-126.

[11] R. Likert, "A Technique for the Measurement of Attitudes," Archives of Scientific Psychology, Vol. 22, No. 140, 1932, pp. 5-53.

[12] J. Schmidt, F. Lamprecht and W.W. Wittmann, "Satisfaction with Inpatient Management. Development of a Questionnaire and Initial Validity Studies,” Psychotherapie, Psychosomatik, Medizinische Psychologie, Vol. 39, No. 7, 1989, pp. 248-255.

[13] E. Brähler, J. Schumacher and B. Strauß, "Diagnostische Verfahren in der Psychotherapie, Hogrefe,” Hogrefe Verlag GmbH \& Co. KG, Göttingen, 2002.

[14] C. C. Attkisson and R. Zwick, "The Client Satisfaction Questionnaire. Psychometric Properties and Correlations with Service Utilization and Psychotherapy Outcome," Evaluation and Program Planning, Vol. 5, No. 3, 1982, pp. 233-237.

http://dx.doi.org/10.1016/0149-7189(82)90074-X

[15] H. Reinecker, "Sorgen-Angst-Furcht. Definition, Ursache, Formen, Sorgenprophylaxe,” 2013.

http://doxatheou.comuf.de/download/seelsorge/Sorgen,\% 20Angst,\%20Furcht.pdf

[16] C. K. Hofer, M. T. Ganter, L. Furrer, G. Guthauser, R. Klaghofer and A. Zollinger, "Patients' Needs and Expectations Regarding Anaesthesia. A Survey on the Pre-Anaesthetic Visit of Patients and Anaesthesiologists,” Anaesthesist, Vol. 53, No. 11, 2004, pp. 1061-1068. http://dx.doi.org/10.1007/s00101-004-0763-4

[17] W. Caumo, A. P. Schmidt, C. N. Schneider, J. Bergmann, C. W. Iwamoto, L. C. Adamatti, D. Bandeira and M. B. Ferreira, "Risk Factors for Postoperative Anxiety in Adults," Anaesthesia, Vol. 56, No. 8, 2001, pp. 720-728. http://dx.doi.org/10.1046/j.1365-2044.2001.01842.x

[18] A. Perks, S. Chakravarti and P. Manninen, "Preoperative Anxiety in Neurosurgical Patients," Journal of Neurosurgical Anesthesiology, Vol. 21, No. 2, 2009, pp. 127130. http://dx.doi.org/10.1097/ANA.0b013e31819a6ca3

[19] J. J. Nightingale, J. A. Lack, J. F. Stubbing and J. Reed, "The Pre-Operative Anaesthetic Visit. Its Value to the Patient and the Anaesthetist," Anaesthesia, Vol. 47, No. 9, 1992, pp. 801-803. http://dx.doi.org/10.1111/j.1365-2044.1992.tb03261.x

[20] C. Soltner, J. A. Giquello, C. Monrigal-Martin and L. Beydon, "Continuous Care and Empathic Anaesthesiologist Attitude in the Preoperative Period: Impact on Patient Anxiety and Satisfaction,” The British Journal of Anaesthesia, Vol. 106, No. 5, 2011, pp. 680-686. http://dx.doi.org/10.1093/bja/aer034

[21] M. A. Kalkhoran and M. Karimollahi, "Religiousness and Preoperative Anxiety: A Correlational Study,” Annals of General Psychiatry, Vol. 29, No. 6, 2007, pp. 1-5. http:/www.ncbi.nlm.nih.gov/pmc/articles/PMC1947984/ pdf/1744-859X-6-17.pdf

[22] E. Twiss, J. Seaver and R. McCaffrey, "The Effect of Music Listening on Older Adults Undergoing Cardiovascular Surgery,” Nursing in Critical Care, Vol. 11, No. 5, 2006, pp. 224-231.

http://dx.doi.org/10.1111/j.1478-5153.2006.00174.x 
[23] A. Agarwal, R. Ranjan, S. Dhiraaj, A. Lakra, M. Kumar and U. Singh, "Acupressure for Prevention of Pre-Operative Anxiety: A Prospective, Randomised, Placebo Controlled Study," Anaesthesia, Vol. 60, No. 10, 2005, pp. 978-981.

http://dx.doi.org/10.1111/j.1365-2044.2005.04332.x

[24] E. E. Werner and R. S. Smith, "Journeys from Childhood to Midlife: Risk, Resilience, and Recovery,” Cornell University Press, New York, 2001.

[25] E. E. Werner, "Journeys from Childhood to Midlife: Risk, Resilience, and Recovery,” Pediatrics, Vol. 114, No. 2, 2004, p. 492. http://dx.doi.org/10.1542/peds.114.2.492

[26] H. Aust, L. H. Eberhart, G. Kalmus, M. Zoremba and D. Rüsch, "Relevance of Five Core Aspects of the Pre-Anesthesia Visit: Results of a Patient Survey," Anaesthesist, Vol. 60, No. 5, 2011, pp. 414-420. http://dx.doi.org/10.1007/s00101-010-1828-1

[27] J. H. Schiff, S. Frankenhauser, M. Pritsch, S. A. For- naschon, S. A. Snyder-Ramos, C. Heal, K. Schmidt, E. Martin, B. W. Böttiger and J. Motsch, "The Anesthesia Preoperative Evaluation Clinic (APEC): A Prospective Randomized Controlled Trial Assessing Impact on Consultation Time, Direct Costs, Patient Education and Satisfaction with Anesthesia Care,” Minerva Anestesiologica, Vol. 76, No. 7, 2010, pp. 491-499.

[28] S. F. Barnett, P. K. Alagar, M. P. Grocott, S. Giannaris, J. R. Dick and S. R. Moonesinghe, "Patient-Satisfaction Measures in Anesthesia: Qualitative Systematic Review," Anesthesiology, Vol. 119, No. 2, 2013, pp. 452-478. http://dx.doi.org/10.1097/ALN.0b013e3182976014

[29] K. I. van der Zee, R. C. Gallandat Huet, C. Cazemir and K. Evers, "The Influence of the Premedication Consult and Preparatory Information about Anesthesia on Anxiety among Patients Undergoing Cardiac Surgery,” Anxiety, Stress, and Coping, Vol. 15, No. 2, 2002, pp. 123-133. http://dx.doi.org/10.1080/10615800290028431 